\title{
Evaluation of the potential utilization of conventional and unconventional biomass wastes resources for energy production
}

\author{
M.Torres ${ }^{1}$, P. Portugau ${ }^{1}$, J. Castiglioni ${ }^{1}$, L. Yermán ${ }^{2}$ and $\underline{\text { A. Cuña }}{ }^{1}$ \\ ${ }^{1}$ Area Fisicoquímica, DETEMA, Facultad de Química - Universidad de la República, Gral. Flores 2124 CC 1157, 11800 \\ Montevideo, Uruguay \\ Phone: +59829248352, e-mail: mtobru@fq.edu.uy, acuna@fq.edu.uy \\ ${ }^{2}$ School of Civil Engineering, The University of Queensland, Brisbane, QLD 4072, Australia \\ Phone: +61733653520, e-mail: 1.yerman@uq.edu.au
}

\begin{abstract}
This work presents kinetic and thermal data of three different biomass wastes with high availability in Uruguay. Samples were analysed by proximate, ultimate and thermogravimetric analyses, transient plane source, and a cone calorimeter. DTG results at different heating rates allowed us to identify different stages during the thermogravimetric analysis. Kinetic modelling per stages was realized for each stage observed during the heating of the biomass samples. The kinetic was modelled minimizing the square difference between the experimental data and theoretical values obtained with the model. Activation energy values were obtained for each stage, with values in the range $164-217 \mathrm{~kJ} \mathrm{~mol}^{-1}$ for the decomposition of cellulose and hemicellulose, and between 190-507 $\mathrm{kJ} \mathrm{mol}^{-1}$ for the decomposition of lignin.
\end{abstract}

\section{Key words}

Kinetic modelling, thermal analysis, biomass, combustion, cone calorimeter.

\section{Introduction}

Biomass as an energy source is gaining interest each year, mainly as a result of governmental policies [1]. The utilization of biomass as energy sources have different advantages, for example: it is of renewable nature, its combustion decreases the greenhouse gas emissions (compared to fossil fuels), the utilization does not compete with agricultural feedstocks, among others [2, 3]. Therefore, nowadays different studies are being developed aiming to develop the direct and indirect utilization of biomass waste as an energy source $[3,4]$.

The utilization of biomass waste as an energy source requires knowing the biomass composition, the thermal transport properties (e.g. thermal conductivity, thermal diffusivity and volumetric heat capacity), as well as the behaviour under different heating rates, the chemical kinetics and the combustion performance.
The aim of this work is to perform a physicochemical and thermal characterization of three biomass waste samples with high availability in Uruguay. The chemical kinetics of the different stages during the combustion process was also modelled. Given the complexity of the processes that involves simultaneous chemical reactions, heat and mass transfer phenomena and heterogeneous reactions, we performed macroscopic analysis. This work aims to shed light on the potential utilization of Uruguayan biomass waste in large fired boilers for energy production.

\section{Methodology}

\section{A. Raw material: selection and classification}

Biomass waste samples were chosen due to its high availability in Uruguay. Selected biomasses are: grape pomace (GP), eucalyptus grandis (EG) and rice husk (RH). GP samples are from a vineyard located in Melilla, Montevideo Department, Uruguay during the grape harvest, and correspond to Tannat type. EG samples come from a 17.5 year-old tree from Piedras Coloradas, Paysandú Department, Uruguay. RH samples were collected from a rice producer located in Rio Branco, Cerro Largo Department, Uruguay and correspond to large seeds of Tacuarí variety. All samples were dried at $105{ }^{\circ} \mathrm{C}$ for 24 hours, crushed and sieved to a particle size below 50 mesh.

\section{B. Ultimate and proximate analysis}

The quantification of $\mathrm{C}, \mathrm{H}, \mathrm{N}, \mathrm{S}$ was carried out with a CHNS/O instrument Thermo Scientific FLASH 2000. The oxygen content was determined by difference. Proximate analysis was performed following the UNIT NBR 8112/1986 standard, using ceramic crucibles and an Isotemp Fischer Scientific muffle. 


\section{Heating value}

The higher heating value (HHV) was determined with a bomb calorimeter Parr 1341, equipped with a 6672precision thermometer. The determination was performed with $c a$. $0.5 \mathrm{~g}$ of sample. The correction for heat of formation of acid was applied, according to the calorimetric bomb manual [5].

\section{Thermal transport properties by transient plane source}

Transient plane source tests (3 for each sample) were carried out at $303 \mathrm{~K}$ using a constant heat power of $50 \mathrm{~mW}$ and a sensor with a radius of $9.868 \mathrm{~mm}$ of Kapton material. Thermal conductivity (k), the thermal diffusivity $(\Omega)$ and the volumetric heat capacity ( $\rho . C p)$ were determined. The sensor was located into a cylindrical recipient (4 cm of radius and $10 \mathrm{~cm}$ of height) containing the samples. Temperature histories of each sample were recorded. A relaxation time of 11520 seconds and a probing depth of $13-15 \mathrm{~mm}$ were used in all the experiments.

\section{E. Thermogravimetric analysis}

Thermogravimetric analysis (TGA) was carried out with a Shimadzu TGA-50. For this analysis, $7.5 \pm 0.2 \mathrm{mg}$ of sample was used in a platinum pan. The air flow was 50 $\mathrm{mL} / \mathrm{min}$ and the temperature ranging from ambient to 950 ${ }^{\circ} \mathrm{C}$. Heating rates used were $5,10,20,30,40$ and $50{ }^{\circ} \mathrm{C}$ $\mathrm{min}^{-1}$. In order to ensure reproducibility, each sample was analysed twice.

\section{F. Kinetic modelling}

TGA data was used to perform the kinetic modelling of the different stages of the combustion process. The fundamental equation that describes the extent of the conversion with the temperature, considering that the kinetic constant follows an Arrhenius expression, can be described by Equation 1:

$$
\frac{d \alpha}{d t}=k_{\infty} e^{-\frac{E_{a}}{R T}} \cdot f(\alpha)
$$

where $\mathrm{k}_{\infty}$ is the pre-exponential factor, $\mathrm{E}_{\mathrm{a}}$ is the activation energy, $\mathrm{R}$ the universal gas constant, $\mathrm{T}$ the absolute temperature, $f(\alpha)$ is a function that describes the reaction progress as function of the conversion and $\alpha$ is the conversion that can be expressed by the Equation 2:

$$
\alpha=\frac{m_{o}-m_{t}}{\left(m_{o}-m_{\infty}\right)}
$$

where $\mathrm{m}_{\mathrm{o}}, \mathrm{m}_{\mathrm{t}}$ and $\mathrm{m}_{\infty}$ are the sample mass at the initial, at the time $t$ and at the end of each process, respectively. The kinetic modelling consists on substituting $f(\alpha)$ as $\alpha^{\gamma}$ and subsequently obtain the solution of the differential equation that describes the conversion progress as a function of the temperature. The model developed is shown in Equation 3

$$
(1-\alpha)=\left[1-\frac{k_{\infty} \cdot R \cdot T^{2}}{\beta \cdot E_{a}} \cdot e^{-\frac{E_{a}}{R \cdot T}} \cdot(1-\gamma)\right]^{\frac{1}{1-\gamma}}
$$

In equation $3, \beta$ represents the heating rate and $\gamma$ is the reaction order. The kinetic parameters $(\mathrm{k} \infty, \gamma \mathrm{y} \mathrm{Ea})$ were obtained by means of an iterative process using Microsoft Excel, and minimizing the square of the total error difference between the experimental data and the values obtained with the Equation 3.

\section{G. Effective heat of combustion}

A cone calorimeter (Fire Testing Technology, i-Cone) was used to quantify the effective heat of combustion

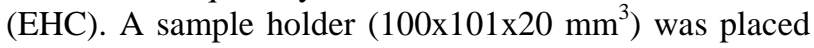
horizontally at $2.5 \mathrm{~cm}$ under a conic heater in order to be exposed to different heat fluxes $\left(20,40\right.$ and $\left.60 \mathrm{~kW} \mathrm{~m}^{-2}\right)$. Experiments were conducted in well ventilated conditions, at an airflow rate of $24 \mathrm{~L} \mathrm{~s}^{-1}$ and using a spark to force the ignition. Measurements were made according to the standardized norm ISO 5660-1. The calculation of the EHC for each sample was determined during the flaming process using the following Equation 4:

$$
E H C=\frac{A \cdot \int_{t_{o}}^{t_{f}} H H R_{(t)} d t}{m_{c}}
$$

where $\mathrm{A}$ is the heat transfer area, $\operatorname{HHR}_{(\mathrm{t})}$ is the heat release rate, $t_{o}$ is the initial flaming time, $t_{f}$ is the burnout time and $\mathrm{m}_{\mathrm{c}}$ is the mass consumed between $\mathrm{t}_{\mathrm{o}}$ and $\mathrm{t}_{\mathrm{f}}$.

\section{Results and discussion}

\section{A. Physicochemical results}

Tables I and II show the characterization results obtained for the different biomass (ultimate and proximate analysis, respectively). RH showed the highest ash content, with lowest $\mathrm{C}, \mathrm{H}$ and VM content. These differences may be responsible for the low HHV of the $\mathrm{RH}$, which is around $30 \%$ lower than the other two samples studied.

Table I. - Ultimate analysis

\begin{tabular}{lccccc}
\hline \multirow{2}{*}{ Sample } & C & H & N & O* $^{*}$ & S \\
\cline { 2 - 6 } & 48.8 & 6.0 & 1.9 & 35.7 & 0.2 \\
GP & 35.3 & 4.7 & 0.3 & 37.8 & 0.1 \\
RH & 48.2 & 5.9 & 0.0 & 46.7 & 0.0 \\
EG & Wt. \% d.b
\end{tabular}

*by difference $=100-\mathrm{C}-\mathrm{H}-\mathrm{N}-\mathrm{S}-\mathrm{Ash}$

Table II. - Proximate analysis and calorific value

\begin{tabular}{lcccc}
\hline \multirow{2}{*}{ Sample } & VM & FC & ASH & HHV \\
\cline { 2 - 5 } & & Wt. \% d.b & & MJ kg $^{-1}$ \\
\hline GP & 72.7 & 19.9 & 7.4 & 20.6 \\
RH & 64.4 & 12.8 & 21.8 & 14.7 \\
EG & 88.5 & 11.3 & 0.24 & 18.7 \\
\hline
\end{tabular}

VM: volatile matter, FC: fixed carbon. All the values are expressed in dry basis (d.b) 


\section{B. Thermal characterization}

The values obtained for the thermal conductivity, the volumetric heat capacity and thermal diffusivity determined by means of TPS are reported in Table III.

Table III. - Thermal transport properties

\begin{tabular}{|c|c|c|c|}
\hline Sample & $\begin{array}{c}\mathbf{k} \\
\mathbf{W} \mathbf{m}^{-1} \mathbf{k}^{-1}\end{array}$ & $\begin{array}{c}\rho \mathrm{C}_{\mathrm{p}} \\
\mathbf{M J} \mathrm{m}^{-3} \mathrm{~K}^{-1}\end{array}$ & $\begin{array}{c}\Omega \\
\mathrm{mm}^{2} \mathrm{~s}^{-1}\end{array}$ \\
\hline GP & $0.096 \pm 0.002$ & $0.913 \pm 0.074$ & $0.106 \pm 0.006$ \\
\hline $\mathbf{R H}$ & $0.114 \pm 0.003$ & $0.947 \pm 0.076$ & $0.120 \pm 0.007$ \\
\hline EG & $0.069 \pm 0.002$ & $0.431 \pm 0.035$ & $0.161 \pm 0.009$ \\
\hline
\end{tabular}

The thermal conductivity value of the RH sample is approximately $19 \%$ and $65 \%$ higher than the GP and EG values, respectively. This fact can be explained due to the high inorganic content (ash) of the RH sample. It is well known that the higher the metal content the higher the thermal conductivity of the material [6].

On the other hand, EG presents a high void space. This effect provokes an increment in the air availably of the sample, which in turn, decreases the thermal conductivity, as the air conductivity if considerably lower than the solids studied. In addition, the ash content in EG is low, which makes the conductivity lower as it was aforementioned.

Regarding to the values obtained for the thermal diffusivity, EG shows the highest value, which means the EG has better ability to transfer the heat wave in comparison to the other samples. Comparing the volumetric heat capacity, which is related with the ability for storing the heat, EG showed the lowest value. This means that EG require less time to reach a certain temperature than the other samples studied.

The performance of the combustion process under different heat fluxes was studied with a cone calorimeter. The EHC for each sample was obtained and then normalized with the HHV obtained from the bomb calorimeter. Table IV shows the ratios EHC/HHV for each sample studied. RH presents the highest EHC/HHV ratios, presumably due to the higher $\mathrm{k}$ and $\rho \mathrm{Cp}$ values (see Table III).

Table IV. - Combustion performance of the samples

\begin{tabular}{lccc}
\hline \multirow{2}{*}{ Sample } & \multicolumn{3}{c}{ EHC / HHV } \\
\cline { 2 - 4 } & $\mathbf{2 0}\left(\mathbf{k W ~ m}^{-\mathbf{2}}\right)$ & $\mathbf{4 0}\left(\mathbf{k W ~ m}^{\mathbf{- 2}}\right)$ & $\mathbf{6 0}\left(\mathbf{k W ~ m}^{-\mathbf{2}}\right)$ \\
\hline GP & 0.388 & 0.556 & 0.624 \\
RH & 0.739 & 0.754 & 0.740 \\
EG & 0.694 & 0.651 & 0.679 \\
\hline
\end{tabular}

In other words, the heat wave is transferred by the sample with less resistance than the other samples and the amount of heat stored by $\mathrm{RH}$ is also higher. Therefore, the combustion temperatures are higher, increasing the combustion efficiency. The influence of the heating power into the combustion efficiency is important for GP, it's increased from 0.388 to 0.624 , meanwhile the effect of the heating power for the other biomass is not as strong as the observed for GP. The low combustion efficiency obtained for GP can be explained by the low thermal properties obtained in Table III.

\section{Thermogravimetric analysis and kinetic modelling}

The thermogravimetric analysis for the biomass samples was carried out at different heating rates under air atmosphere. Differential of the mass loss thermogravimetric analysis (DTG) as a function of the temperature is shown in Fig. 1. Different reaction steps can be identified to occur during the combustion process. This data allowed us to develop a kinetic model for the different steps identified.

During the heating and combustion of the biomass samples, different processes are taking place. For GP and EG it was possible to identify four processes: moisture loss (1), decomposition of cellulose (2) and hemicellulose (3) and decomposition of lignin (4). Nevertheless, RH sample showed one combined stage for 2 and 3, as both processes take place in the same temperature range. In order to analyse the behaviour of the combustion process during the heating of the samples, the combustion characteristic index $(\mathrm{S})$, was calculated. The $\mathrm{S}$ value is used as an empirical index with high accuracy that describes the combustion processes and it can be expressed by the Equation 5 [7]:

$$
S=\frac{\left(\frac{d m}{d t}\right)_{\max } \cdot\left(\frac{d m}{d t}\right)_{\text {media }}}{T_{i}^{2} \cdot T_{f}}
$$

Where $(\mathrm{dm} / \mathrm{dt})_{\max }$ and $(\mathrm{dm} / \mathrm{dt})_{\text {media }}$ represent the maximum weight loss rate and the average weight loss rate of the process respectively. $T_{i}$ is the ignition temperature and $\mathrm{T}_{\mathrm{f}}$ the burnout temperature of the process assessed. Higher $\mathrm{S}$ values indicates more active combustion reaction [7].

Table $\mathrm{V}$ shows the different $\mathrm{S}$ values calculated from Equation 5. As a general trend, the combustion index increases with the heating rate. This fact can be explained because when the heating rate increases, the processes take place at higher temperatures, and therefore the reaction rate increases. As the ash content increases in the samples, the combustion efficiency diminishes because the presence of incombustible material decreases the combustion efficiency [7]. It was observed that above heating rates of $40{ }^{\circ} \mathrm{C} \mathrm{min}^{-1}$, the $\mathrm{S}$ value obtained for EG is above $2 \mathrm{mg}^{2} \mathrm{~s}^{-2}{ }^{\circ} \mathrm{C}^{-3}$, which means that the combustion processes is dynamic and it can be used as fuel in large fired boilers for energy production [8, 9]. For RH, the aforementioned behaviour is observed only for a heating rate of $50{ }^{\circ} \mathrm{C} \mathrm{min}^{-1}$. 
a)

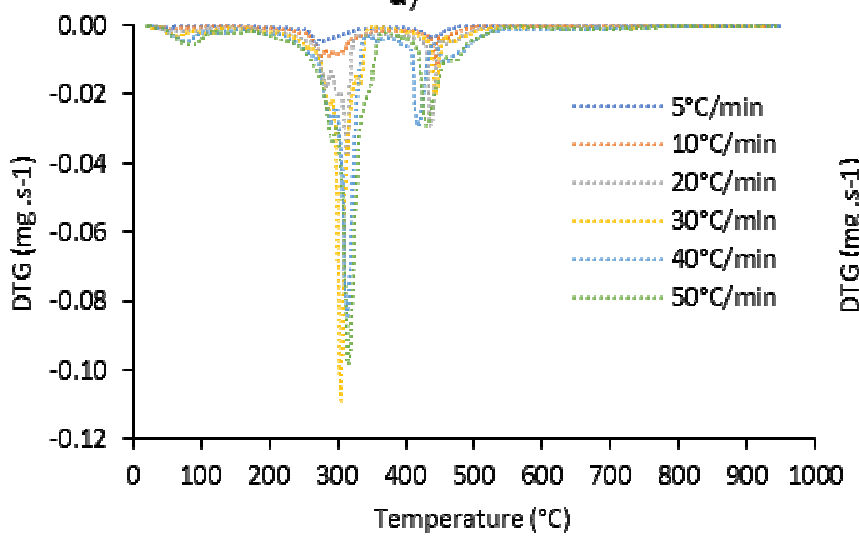

b)

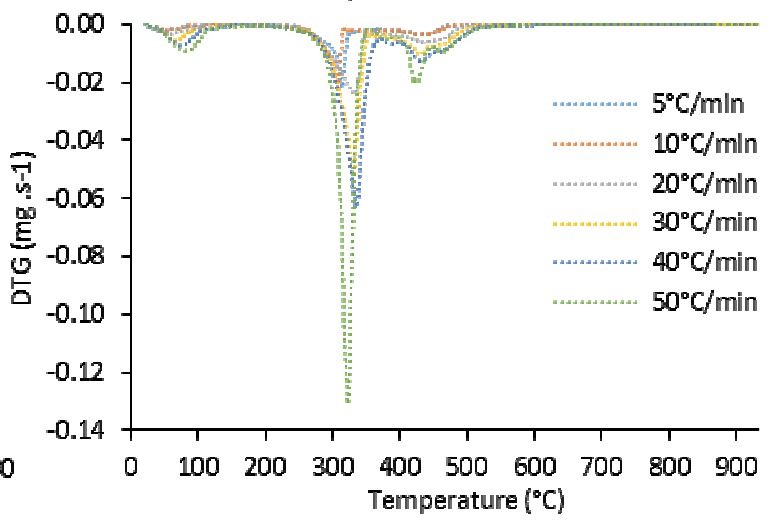

c)

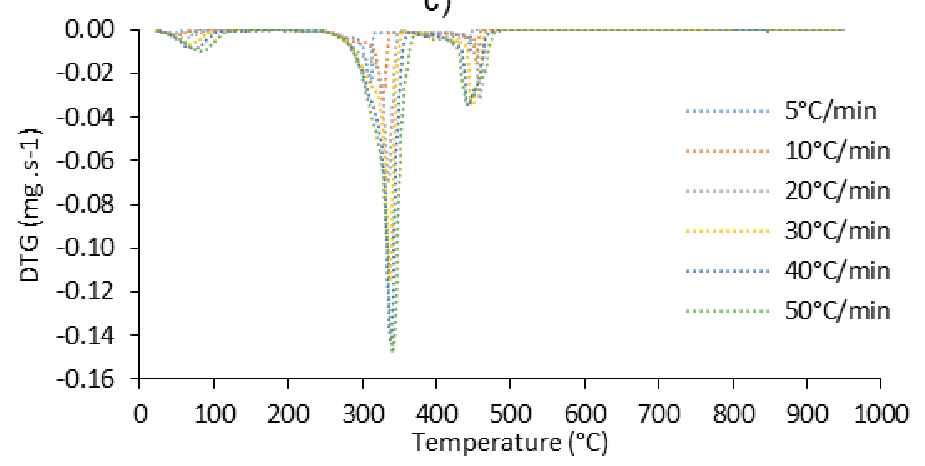

Figure 1. Differential thermogravimetric analysis (DTG) curves obtained at different scan rate in air atmosphere, for the sample: a) GP, b) RH and c) EG.

Table V. - Calculated $\mathrm{S}$ factor

\begin{tabular}{cccc}
\hline $\boldsymbol{\beta}$ & \multicolumn{3}{c}{$\mathbf{S}\left(\mathbf{1 0}^{\mathbf{1 0}} \mathbf{~ m g}^{\mathbf{2}} \mathbf{s}^{-2}{ }^{-} \mathbf{C}^{-3}\right)$} \\
\cline { 2 - 4 }$\left({ }^{\circ} \mathbf{C} \mathbf{~ m i n}^{-\mathbf{1}}\right)$ & $\mathbf{G P}$ & $\mathbf{R H}$ & $\mathbf{E G}$ \\
\hline 5 & 0.01 & 0.07 & 0.05 \\
10 & 0.01 & 0.08 & 0.12 \\
20 & 0.25 & 0.12 & 0.44 \\
30 & 1.20 & 0.38 & 1.14 \\
40 & 1.03 & 0.57 & 2.04 \\
50 & 1.28 & 2.09 & 2.47 \\
\hline
\end{tabular}

To evaluate the kinetic parameters of the processes involved during the combustion of the samples (e.g. decomposition of cellulose, hemicellulose and lignin) the experimental data from TGA analysis was fitted using the model proposed in Equation 3. The optimized kinetic parameters for the three samples are summarized in Table VI. Process 3 for RH is not possible of modelling because this stage is overlapped with the processes 2 . Due to this fact, both processes were modelled simultaneously.
Table VI. - Optimized kinetic parameters

\begin{tabular}{|c|c|c|c|c|}
\hline Process & Parameter & GP & RH & EG \\
\hline \multirow{3}{*}{2} & $\log \left(k_{\infty}\right)$ & 15.31 & 18.23 & 17.15 \\
\hline & $\begin{array}{c}\mathrm{E}_{\mathrm{a}} \\
\left(\mathrm{kJ} \mathrm{mol}^{-1}\right)\end{array}$ & 168 & 204 & 196 \\
\hline & $\gamma$ & 1.38 & 2.15 & 1.26 \\
\hline \multirow{3}{*}{3} & $\log \left(\mathrm{k}_{\infty}\right)$ & 13.28 & - & 17.39 \\
\hline & 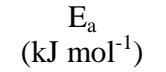 & 165 & - & 217 \\
\hline & $\gamma$ & 2.97 & - & 4.31 \\
\hline \multirow{3}{*}{4} & $\log \left(k_{\infty}\right)$ & 29.00 & 14.48 & 37.39 \\
\hline & $\begin{array}{c}\mathrm{E}_{\mathrm{a}} \\
\left(\mathrm{kJ} \mathrm{mol}^{-1}\right)\end{array}$ & 349 & 190 & 508 \\
\hline & $\gamma$ & 3.35 & 3.12 & 4.62 \\
\hline
\end{tabular}

The activation energy for the GP and EG samples increases with the temperature, meaning that the combustion process is less favourable. This behaviour is the opposite observed for the RH sample, whose Ea value slightly diminish as the temperature increases. Furthermore, those parameters fit well with the experimental data obtained at low heating rates. On the other hand, for high heating rates the model predicts the values with a $10 \%$ of error for some $\alpha$ values. 


\section{Conclusions}

Three different biomass samples were characterized from a physicochemical, thermal and kinetic point of view. RH and EG seem to have suitable characteristics to be used in large fired boilers for the energy production. It is important to highlight hat these results were obtained for a particle size less than 50 mesh. In order to study the process at a larger scale, analyses with larger particle size should be carried out.

\section{Acknowledgement}

The authors thank the National Research and Innovation Agency of Uruguay (ANII) for the financial support, project ANII_FSE_1_2016_1_131635. Chem. Eng. Torres thanks for the master's scholarship POS_NAC_2016_1_129893 and also to PEDECIBAQUIMICA and CSIC-Udelar for the economic support granted to carry out a research internship in the Fire and Combustion Laboratories of the University of QueenslandAustralia. The authors also thank the Sociedad Anónima Molinos Arroceros Nacionales (SAMAN) for the rice husk samples, to Amendola Hnos and Boido vineyard for grape pomace samples and UPM Forestal Oriental for Eucaliptus grandis samples.

\section{References}

[1] "Celebración de contratos de compraventa para la producción de energía eléctrica a partir de biomasa (Decreto $N^{\circ}$ 367/010)", Uruguay, 2010. [Online]. Available online: https://www.impo.com.uy/bases/decretos/367-2010 [Accessed 7 Nov. 2018].

[2] M. Castelli, "Evaluación de Proyectos de Microgeneración Basados en Biomasa", Consultoría de apoyo al Componente: Políticas Energéticas 2005-2030, Eje Estratégico: Diversificación de la Matriz Energética, Ministerio de Industría, Energía y Minería, Dirección Nacional de Energía, Uruguay, 2010. [Online]. Available online: http://www.miem.gub.uy/sites/default/files/evaluacion_de_proye ctos_de_microgeneracion_basados_en_biomasa.pdf [Accessed 7 Nov. 2018].

[3] E.G.A. Forbes, R.J. Olave, C.R. Johnston, J.D. Browne, J. Relf, "Biomass and bio-energy utilisation in a farm-based combined heat and power facility", Biomass and Bioenergy, Vol. 89, pp. 172-183, 2016.

[4] L. Cutz, P. Haro, D. Santana, F. Johnsson, "Assessment of biomass energy sources and technologies: the case of Central America", Renewable and Sustainable Energy Reviews, Vol. 58, pp. 1411-1431, 2016.

[5] "204M 1341 Plain Jacket Calorimeter Operating Instructions", [Online]. Available online: https://www.parrinst.com/products/oxygenbombcalorimeters/1341-plain-jacket-bomb-calorimeter/documents/ [Accessed 24 May 2018].

[6] O. D. Akinyemi, J. A. Olowofela, O. O. Akinlade, \& O. O. Akande, "Thermal conductivity of soils with heavy metals concentration from the Niger Delta region of Nigeria", Journal of Zhejiang University. Science. B, 7(8), 615-8, 2006.

[7] Z. Yao, X. Ma, Z. Wang, L. Chen, "Characteristics of cocombustion and kinetic study on hydrochar with oil shale: a thermogravimetric analysis", Applied Thermal Engineering, Vol. 110, pp. 1420-1427, 2017.

[8] Y. Fan, Z. Yu, S. Fang, Y. Lin, Y. Lin, Y. Liao, X. Ma, "Investigation on the co-combustion of oil shale and municipal solid waste by using thermogravimetric analysis", Energy Conversion and Management, Vol. 117, pp. 367-374, 2016.

[9] G. K. Parshetti, A. Quek, R. Betha, R. Balasubramanian, "TGA-FTIR investigation of co-combustion characteristics of blends of hydrothermally carbonized oil palm biomass (EFB) and coal", Fuel processing technology, Vol. 118, pp. 228-234, 2014. 